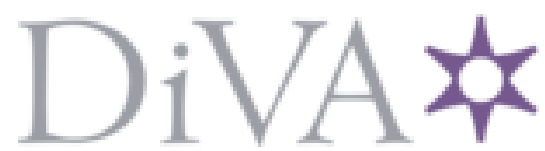

http://www.diva-portal.org

\title{
Postprint
}

This is the accepted version of a chapter published in Oxford Handbook of Reasons and Normativity.

Citation for the original published chapter:

Glüer-Pagin, K., Wikforss, Å. (2017)

Reasons for Belief and Normativity.

In: Daniel Star (ed.), Oxford Handbook of Reasons and Normativity Oxford University Press

N.B. When citing this work, cite the original published chapter.

Permanent link to this version:

http://urn.kb.se/resolve?urn=urn:nbn:se:su:diva-138151 


\section{Reasons for Belief and Normativity}

Kathrin Glüer and Åsa Wikforss

Forthcoming in Oxford Handbook of Reasons and Normativity, ed. Daniel Star, Oxford: OUP.

\section{Introduction}

What I see when I look into the fridge gives me reason to believe that there is beer in there. What the mechanic at the garage tells me gives me reason to believe that repairing my car will be expensive. What I know about Paul gives me reason to believe that Paula will be angry with him. I might or might not believe what I have thus been given reason to believe. I might have other, better reasons not to believe it. I might be uninterested or inattentive. What I have been given reason to believe might be patently absurd. But if nothing like this is the case, and the reason in question is sufficiently strong - then it would be rational to believe what it is a reason for. And doesn't that mean that I ought to believe it? Moreover, isn't doing what I ought to do, in this sense, precisely what it means to have a justified belief?

When it comes to reasons for belief, considerations like these often seem to lie behind the rather broad consensus that reasons are normative. Slogans of the form $x$ is normative are popular across current philosophy of mind and language as well as epistemology, but there usually isn't much of a consensus on what that precisely means. In contrast to other such slogans, not much argument has yet been offered for the normativity of reasons, however. Their normativity is pretty much taken for granted.

In this article, we shall critically examine the most important extant ways of understanding and motivating the idea that reasons for belief are normative. We shall assume that the normativity in question is supposed to be an essential feature of reasons for belief. We shall also assume that the normativity in question is the prescriptivity of genuine oughts, and that merely instrumental norms won't qualify. Moreover, we shall assume that the normativity we are after is not derivative, i.e. that it is the reasons themselves, or the relation of 
being a reason for, that is the source of the wanted normativity - not the concept or ethics of belief, for instance.

We shall proceed as follows. First, we shall examine the proposal that the distinction between explanatory and so-called normative reasons that is commonly drawn in moral philosophy can be rather straightforwardly applied to reasons for belief, and that reasons for belief are essentially normative precisely when they are normative reasons (section 2). In the course of this we shall explore the very nature of the reasons-for-belief relation, as well as the ontology of such reasons. Second, we shall examine the idea that the normativity derives from the internal connection between reasons for belief and epistemic justification, distinguishing between two distinct normativist accounts of justification, a weaker and a stronger one (section 3). We shall argue that neither line of argument is compelling. Pending further arguments, we conclude that normativism about reasons for belief is not supported.

\section{Reasons for Belief as Normative Reasons}

Moral philosophers writing about reasons distinguish between explanatory and normative reasons (or motivational and justificatory reasons). ${ }^{1}$ It is easy to see the initial plausibility of such a distinction when thinking about reasons for action. The reasons we might cite to explain why someone performed a particular action $\varphi$, and the reasons we think there were for her to $\Theta$, might come apart: People might be motivated to $\Theta$ by things that do not genuinely justify, "count in favour of" or "speak for" Eing at all. A normative reason, then, is supposed to be a consideration that genuinely speaks for performing an action of a certain type. Even though normative reasons can be, and most often are, prima facie or pro tanto reasons, they are all good reasons in the sense of genuinely speaking for $\Theta i n g$. Following Scanlon, many moral philosophers think that this notion of a reason does not allow for further substantive explication and therefore must be taken as primitive. ${ }^{2}$

\footnotetext{
${ }^{1}$ Neither distinction is crystal clear. Nor is it clear whether there really are two distinctions here, or just one. See Lenman 2009 for a survey.

${ }^{2}$ Scanlon 1998, $17 \mathrm{ff}$.
} 
Normative reasons for action might then be thought of as normative in the following, basic sense: If a reason $R$ genuinely justifies or speaks for an agent $S$ performing an action of type $\Theta$, then $S$ (prima facie at least) ought to $\Theta$. Some locate the very roots of normativity in what we can all the "reasons relation", i.e. the relation between a reason and what it is a reason for. The reasons relation thus has come to be seen as the normative relation par excellence. ${ }^{3}$ Moreover, reasons in this sense might not only be thought of as "ought generating" in this basic way, but as normative in a stronger sense as well: Reasons that genuinely speak for actions are such that they guide rational action. An agent $S$ who is guided by a reason $R$ for $\Theta$ ing not only $\Theta \mathrm{s}$, but does so for that very reason. This is often taken to require the capacity to recognize a reason $a s$ a reason.

The distinction between explanatory and normative reasons is often taken to be straightforwardly applicable to reasons for belief, too. And we certainly explain beliefs by all sorts of things, things that on closer inspection aren't any good as reasons, or aren't reasons at all. So, one might think that normative reasons for belief are those considerations that genuinely speak for forming a belief. If that is correct, normative reasons for belief simply would be a certain species of normative reason, and their normativity could be understood on the model of that of normative reasons for action. In this section, we shall explore the application of the explanatory-normative distinction to reasons for belief.

\subsection{Explanatory and Normative Reasons}

The first question concerns the very motivation for drawing the explanatorynormative distinction for reasons for belief. For even though we routinely explain beliefs by things that do not genuinely speak for them, it is by no means clear that these things are reasons. Thus, the explanation for my believing that there is beer in the fridge might be that someone knocked me on the head, but while the knock might be the cause of my belief, there is no sense in which it is a reason. All sorts of things can explain the formation of beliefs, but to be an explanatory reason, we take it, it is not sufficient to be explanatory. Rather, if $x$ is the explanatory reason for a belief that $p$, we can give a reasons explanation for that belief by means of $x$. But if explanatory reasons are those that provide

\footnotetext{
${ }^{3}$ See for instance Olson, this volume, Raz 2011, 85 .
} 
reasons explanations for our beliefs, it becomes much less clear that these reasons can diverge radically from those that genuinely speak for those beliefs.

A veritable tradition going back to Davidson has it that all reasons explanations are such that they "rationalize" what they explain, i.e. show what speaks for the action or belief from the subject's own perspective. To a certain extent, the rationality involved is subjective in at least three senses. First, to speak for something from the subject's own perspective, a reason needs to be related to the subject in a certain way. Davidson took this to limit the domain from which to draw explanatory reasons to that of the propositional attitudes. Second, an explanatory reason might be such that neither those who give the explanation, nor those who receive it, need to share the reason with the subject of the explanation. Thus, I can explain to you both why $S$ runs to the bus stop and why she believes that she'll make it to the meeting by citing her belief that the bus is on time -- even if we both know the bus to be late. Thus and third, beliefs cited in reasons explanation do not have to be true.

Nevertheless, there are clear limits to the subjectivity of reasons explanation for belief. We might explain a belief that $q$ by a belief that $p$ even if we do not believe $p$ ourselves. But not any old $p$ will do. Rather, $p$ and $q$ need to be related in such a way that even those who do not believe $p$ can see that if they did that would speak for also believing $q$. The explanatory force of reasons explanations for belief thus depends on the presence of an objective - or at least inter-subjective - reasons relation. Let's call this the "objectivity requirement on reasons explanations for belief" or the "objectivity requirement" for short. 4,5

\footnotetext{
${ }^{4}$ An anonymous referee finds the objectivity requirement too strong. Their example: "Suppose you believe that vaccines cause autism because your cousin's friend's son developed behavioural problems soon after his MMR shot. It seems plausible that this provides an explanatory reason for your belief. This is so even if I don't think that this 'speaks for' the belief that vaccines cause autism." If we remember that the reasons we are talking about are prima facie reasons, the example in fact provides a good illustration of our point: that someone developed behavioural problems soon after a vaccine certainly is some, even though in isolation extremely weak, evidence of there being a causal connection. Believing this thus to a certain weak degree speaks for believing that vaccines cause autism. Note, too, that in this case we both believe that someone developed behavioural problems soon after a vaccine. The case is thus not one where our reasons aren't the same. Rather, I draw an all things considered unwarranted conclusion from a shared reason. That is, my belief formation is irrational. What this illustrates is that even in case of such epistemic irrationality, the irrationality is limited as long as a reasons-explanation is still available: I do have a reason that speaks for my conclusion, but this reason is either totally outweighed by other considerations, or simply too weak to ever just form a belief on. Nevertheless, there would be no reasons explanation if what we both believe did not at all speak for the conclusion I actually draw.
} 
It is of course a very good question what the precise nature of the required relation is. But it seems fairly clear that, intuitively, speaking for is one and the same relation - regardless of whether it holds between a normative reason for believing that $p$ and believing that $p$ or between a reason the having of which explains a belief that $p$ and believing that $p$. Let's call this the "same relation requirement". Together, the objectivity and the same relation requirement substantially constrain plausible accounts of reasons for belief.

For one thing, the same relation requirement fuels the sense that for reasons for belief, the explanatory-normative distinction might be hard to motivate. Maybe the best way of satisfying the same relation requirement is to say that, for belief, there is only one kind of reason (cf. Turri 2009).

Moral philosophers have pushed related claims of identity between explanatory and normative reasons for action (cf. for instance Williams 1979, Scanlon 1998, Dancy 2000). To take a recent example, Heuer writes that "[t]he identity thesis - the claim that justificatory and explanatory reasons are the same reasons - seems crucial for our understanding of ourselves as practically rational" (Heuer 2004, 46). Heuer is very clear, however, that this identity thesis "should be taken in a weak sense, allowing there to be justificatory reasons that did not motivate (hence, that cannot explain a person's action) and explanations which are not justificatory. It amounts simply to the claim that justificatory reasons are in principle capable of explaining what we do" (ibid.). Such identity theses thus amount to conditional possibility claims of something like the following form:

$\left(\mathrm{I}_{\mathrm{NE}}\right) \quad$ For all $x$, if $x$ is a normative reason for $\Theta$ ing then it is possible that there is a $\varphi$ such that the having of $x$ explains $\varphi$.

What $\left(\mathrm{I}_{\mathrm{NE}}\right)$ enforces is a restriction on the extension of normative reason: It contains only a certain kind of object, the kind of object the having of which is

\footnotetext{
${ }^{5}$ It is not immediately obvious in how far the objectivity requirement just carries over to action explanation. Arguably, it holds even for action explanations by means of desires (or belief-desire pairs). To have explanatory force, citing a desire to explain an action, that desire needs to be such that its speaking for the action is intersubjectively appreciable. And many people think that there are limits to what a person can rationally desire, i.e. to the contents of the desires that can be cited in reasons explanations. David Lewis, for instance, was fond of illustrating this with the example of desiring a saucer of mud without having any idea what would be good about it (Lewis 1996, 306, example originally from Anscombe 1958). But even if it is right that no rationalization is to be had from this "desire", the underlying relation between a desire reasons explaining an action might be rather different from that underlying the relation between a belief explaining a further belief.
} 
capable of explaining action. ${ }^{6,7}$ But when it comes to reasons for belief, we might want to complement (the belief version of) ( $\left.\mathrm{I}_{\mathrm{NE}}\right)$ with a claim like $\left(\mathrm{I}_{\mathrm{EN}}\right)$ :

(IEN) For all $x, p$ : if there is a belief that $p$ explained by the subject's having $x$, then $x$ is a normative reason for believing that $p$.

( $\mathrm{IEN}_{\mathrm{EN}}$ ) does not exclude the possibility of there being normative reasons for belief that do not explain any actual beliefs. But it does exclude the possibility of there being any beliefs that are explained by reasons that are not normative reasons for them.

( $\left.\mathrm{I}_{\mathrm{EN}}\right)$ will strike many as implausible. But maybe it shouldn't. The reasons we are concerned with are all prima facie reasons. ( $\mathrm{I}_{\mathrm{EN}}$ ) only demands that all the prima facie reasons actually explaining beliefs are also reasons that, prima facie, speak for believing those things. It does not exclude the possibility of wildly unjustified or internally irrational belief. Moreover, so far we know very little about what it even means to (have reasons that) speak for believing something.

Nevertheless, you might think that when it comes to reasons for belief, speaking for clearly comes in two flavors, so to speak: normative speaking for is closely tied to epistemic justification and evidence, while explanatory speaking for is not. An explanatory reason for a belief that $p$, one might thus think, need not be such that having it provides epistemic justification for believing $p$. Whether or not we can hold on to the same relation requirement in the face of such

\footnotetext{
${ }^{6}$ How substantive a claim this is depends, of course, on the kind of possibility and the kind of agent and circumstances invoked in $\left(\mathrm{I}_{\mathrm{NE}}\right)$. Does it hold for ideally rational agents under ideal circumstances, or for agents like us? And what is the intended direction of explanation here? Does the force of normative reasons derive from their power to explain? Or vice versa? Cf. Finlay and Schroeder 2008.

${ }^{7}$ However, $\left(\mathrm{I}_{\mathrm{NE}}\right)$ is compatible with a same relation requirement. Of course, the relation of speaking for and that of explaining an action are not the same: Speaking for takes types of action as its second relatum, while explanation takes particular actions. A same relation requirement is not directed at the explanation relation, however. It is directed at the relation of speaking for that needs to obtain for a reason to be able to explain a particular action. And that is a relation taking types of action as its second relatum. And analogously for reasons for belief, of course.

${ }^{8}$ Michael Smith (2004) argues for one (pretty radical) version of such divergence. He argues that motivated belief ipso facto is irrational belief, i.e. that reasons explaining belief cannot be normative reasons. (According to Smith, reasons explanations are belief-desire explanations; so, motivating reasons are mental states - but normative reasons aren't.) Timothy Williamson (2000) argues for another version of such divergence. According to Williamson, evidence equals knowledge. Consequently, one might say, only knowledge provides a subject $S$ with normative reasons for further beliefs. But all of $S$ 's beliefs, be they knowledge or not, can be cited in reasons explanations of $S$ 's further beliefs.
} 
considerations depends, among other things, on the ontology of reasons. We shall turn to that now.

\subsection{What kind of an animal is a reason?}

What ontological category do reasons belong to? Here are the main candidates: propositions, states of affairs or facts, and mental states such as propositional attitudes. Some writers think that both explanatory and normative reasons belong to one and the same ontological category, and some think that explanatory and normative reasons are different kinds of animal. ${ }^{9}$

Propositional attitudes might seem attractive candidates for being reasons for belief. Thus, Davidson (in)famously declared: "Nothing can count as a reason for holding a belief except another belief" (Davidson 1983, 141). And it seems clear that, to figure in reasons explanations, the relevant reasons need to be "had" by the subject of the explanation. Propositional attitudes (or mental states in general) are therefore at least natural candidates. But it is at least equally plausible to construe the reason as the proposition itself, and the relevant having as the having of an attitude towards that proposition. ${ }^{10}$ We can then speak of the relevant attitude as "providing its subject with a reason", where the reason is the proposition the attitude is an attitude towards.

Both proposals might seem too narrow, however. Many have held that perception provides its subjects with reasons for belief (cf. McDowell 1994, Brewer 1999). If reasons require or are propositions, those who think that experiences don't have propositional contents, or any contents at all, won't be

\footnotetext{
${ }^{9}$ Proponents of propositions include Scanlon (1998) and Brandom (2000), facts or states of affairs are favored by, among others, Dancy (2000), Raz (2011), and Smith (2004, for normative reasons), and mental states by Smith (2004, for motivational reasons) and Turri (2009, for reasons for belief in general).

${ }^{10}$ One of us has argued that Davidson himself can plausibly be read this way (cf. Glüer 2011, 117f; 227ff; Glüer 2012). When Davidson argues for his "belief only"-claim, he in effect runs two arguments together. The first argument turns on the premise that reasons need to stand in inferential or evidential relations to one another. Only propositions will do for this job. The second argument starts from the premise that the reason needs to be the subject's. Together, this means that a propositional attitude is required. Davidson's main point, however is this: the attitude needs to be one of holding true, i.e. belief. Simply put: you need to hold a proposition true in order to have a reason for actually drawing any consequences from it. Just entertaining it, or desiring its truth, won't do. Since it isn't the beliefs, but their contents that stand in inferential or evidential relations, it is therefore best to read Davidson as saying that only beliefs are such that they provide their subjects with reasons for further beliefs.
} 
able to account for the reasons providing role of perception. ${ }^{11}$ One option would be to think of reasons as mental states more generally. Turri argues that even on the assumption that perceptual experiences have propositional contents, perception provides an argument against what he calls "abstractionism": the view that reasons are propositions. We "ought to reject abstractionism because it entails that to heed the call of experience is to move in a circle. Not a hint of circularity infects such a transition" (Turri 2009, 498). Thus, if I believe that there is beer in the fridge on the basis of looking into it, abstractionism would have to understand that as a transition from there is beer in the fridge to there is beer in the fridge. Now, it is not only controversial whether the reasons provided by experience are indeed "inferential" in the sense here presupposed. It is also controversial whether the justificatory role of experience is to be understood in terms of reasons at all. Moreover, Turri's argument presupposes that experiences indeed have the very same contents as the beliefs based on them. But the very fact that basic inferences from experience would then "stutter" could be used as an argument against that premise. ${ }^{12}$

Turri also provides an independent "master argument for statism": the view that reasons for belief are mental states. According to Turri, if we want to understand your reasons for believing something, "having the relevant mental states in place and appropriately related is both necessary and sufficient" (Turri 2009, 504). This observation is best explained by statism, because statism does not require introducing any further items into the reasons explanation, Turri claims. As long as the states cited in reasons explanations are propositional attitudes, however, it is hard to see how identifying reasons with propositions would introduce anything that wasn't already needed anyway. ${ }^{13}$

${ }^{11}$ Brewer now argues that experiences do not have any content (joining philosophers such as Mike Martin (2002) and Charles Travis (2004) on this). McDowell now thinks that perceptual content is not propositional. Tyler Burge (2010) and Tim Crane (2009) hold similar positions.

12 So-called "stuttering inference arguments" have been put to a variety of uses. McDowell uses a stuttering inference argument against construing the reasons perception provides as inferential reasons (1998). Glüer (2009), by contrast, uses such an argument for the claim that experiences do not have the same contents as beliefs based on experiences. Siegel and Silins (2013) survey the epistemology of perception.

${ }^{13}$ And as long as facts are understood as true propositions, no new items are introduced by construing reasons as facts, either. 
Dancy provides influential arguments against both propositions and mental states as reasons. Mental states, he argues, cannot be (explanatory or motivating) reasons for belief because if they were it would be impossible for us to ever believe something for the (normative) reasons speaking for believing it: "The reasons why we believe something will always be other psychological states of ours, never anything like the evidence available to us" (Dancy 2000, 105). Others have argued more generally that our reasons for believing $p$ (almost) never are things like that we believe that $q$, but rather things like that $q$. But even though this is very plausible, it does by no means follow that having $q$ as a reason, and explaining why a subject $S$ believes that $p$ by means of $S$ 's having that reason do not essentially involve $S$ 's having a mental state with the content that $q$.

However, Dancy and others also argue that only facts or states of affairs can be normative reasons. One popular argument for facts and against propositions is that while belief in a false proposition $p$ might explain why someone believes $q$, in such a case there is no genuine (normative) reason for believing $q$ (cf. for instance Olson, this volume). To the extent that this is based on ordinary language use - we do say things like "there was no reason for him to run to the bus stop as the bus was late, as usual" - the evidence is inconclusive at best, as it seems equally natural to say things like "his/my reason for running to the bus stop was that he/I believed that the bus was on time".

Even if all reasons were propositions, one could argue that normative reasons for belief are to be identified with true propositions. It is, one might hold, only true propositions that genuinely speak for believing something. It has been argued that this claim derives from the ethics of belief itself, as one ought to believe something only if it is true (cf. Raz 2011, 97ff). But the ethics of belief is not only a different, highly controversial topic - if it is the source of the normativity of reasons, this normativity is derivative, and not what we are looking for. ${ }^{14} \mathrm{~A}$ better idea might be to argue along lines like these: your epistemic situation is good only in the so-called good case where you base your belief that $q$ on a true belief (or, as Williamson (2000) has it, on knowledge) that

\footnotetext{
${ }^{14}$ For more on the normativity of belief, see Hattiangadi, this volume.
} 
p. One might then say, for instance, that all reasons are propositions, but only true (or known) propositions are normative reasons for belief.

But Dancy also provides a completely general argument against propositions as reasons. Propositions, he says, can be construed in either of two ways: as structured, sentence-like objects or as sets of possible worlds. And neither is "the sort of thing to make an action sensible or right" (Dancy 2000, 115). We are not quite sure what to make of this, especially when considering how to apply it to reasons for belief. It is not clear what it is for a belief to be "sensible or right". If this means that the belief is true, surely a reason for holding it is not what makes it true. If "sensible or right" means that it is rational or epistemically justified for the believer to hold the belief, then it is far from obvious that what makes it so are facts or states of affairs - rather than things the believer believes or knows. ${ }^{15}$

Moreover, if you believe that reasons only come in one ontological flavor as Dancy clearly does - construing them as facts or states of affairs generates serious problems for explanatory reasons. When it comes to reasons explanations, false beliefs do a lot of explanatory work for us. How is that even possible if all reasons are facts or states of affairs? It might be tempting to talk of "facts as the agent conceives them to be" here, but in the case of a false belief, there simply is no relevant fact. ${ }^{16}$ There is a false proposition, however (held true by the believer).

To our minds, the most plausible conclusion to be drawn from these considerations is that reasons for belief are best construed as propositions. As we said, this is not to deny that reasons explanations essentially involve

${ }^{15}$ When it comes to states of affairs, moreover, one might well ask whether it is so clear that they are so radically different from propositions. To be sure, propositions are true or false, while states of affairs obtain or don't obtain. But many people think that states of affairs are complex entities having constituents, and that these constituents are objects and properties somehow forming the complexes. On a so-called "Russellian" way of understanding propositions, propositions would seem to be very similar entities, indeed.

${ }^{16}$ Dancy $(2000,131 \mathrm{ff})$ bites the bullet here and claims that there are non-factive explanations. Raz (2011, 34f) "goes meta" and claims that the agent's belief that there are reasons can motivate even if there are none: "As the agent sees matters, it is as if there are reasons, and they motivate him, even when he does not know what they are, and even though they are not there." But first of all, it is by no means clear that to have a (motivating) reason one needs to believe that one has one, and second, all the explanatory work is now done by the belief that there are reasons. It is simply no good to protest: "But the motivating power of these beliefs exists in the shadow of the motivating power of the reasons" (ibid.) - something that does not exist does not cast any shadows, either. 
propositional attitudes - we can only explain a subject $S$ 's belief that $q$ by means of a reason $p$ if $S$ has that reason. On the assumption that reasons are propositions, having reason $p$ can quite plausibly be understood as standing in one of attitudinal relations to $p$. But which? Does having a reason for belief require a cognitive attitude, such as belief? More generally, can there be practical reasons for belief? This is the question we shall turn to now.

\subsection{Practical reasons for belief?}

Davidson thought that only beliefs provide reasons for further belief. This, of course, is not to deny the existence of what Michael Smith would call "motivated belief", i.e. belief formed under the influence of desire (Smith 2004). But is motivated belief necessarily irrational, as Smith thinks? More generally, can there be practical reasons for belief?

Many think that there cannot be practical reasons for belief. Belief formed on the basis of practical reasons is necessarily irrational. ${ }^{17}$ It might, however, be possible to hold on to that idea and nevertheless think that there are practical reasons for belief, even good ones. The irrationality that necessarily comes with motivated belief, one might say, is epistemic. And even though belief formed under the influence of desire (or for practical reasons) always is epistemically irrational, it might not be irrational or unjustified in other respects, moral respects, for instance, or even all things considered.

If belief can be rational, or irrational, in different respects - epistemically, morally, prudentially, etc. - the question would be how these respects relate to one another. Are they incommensurable, as is often held (Kelly 2003)? Or can epistemic and other reasons for belief be weighed against one another? Such that there is such a thing as what one has reason to believe, all things considered? If so, how do we integrate practical and theoretical reasoning into one model? A worry here would seem to be this: models of practical reasoning usually have a slot for belief. If a belief is rational only if the subject's reasons for holding it can be rationally reconstructed as a piece of reasoning, and every such piece of reasoning requires another belief, being rational might easily become a supertask. And even though it might not be possible for us to ever be fully

\footnotetext{
${ }^{17}$ See a.o. Smith (2004), Raz (2011), Shah and Velleman (2005), and Kelly (2003). For some recent dissent, see: Booth (2013), McHugh (2013), Reisner (2009).
} 
rational, it is surely absurd to consider forming even a single rational belief a supertask. ${ }^{18}$

Another important question in this area is the question of voluntariness or control. It is often claimed that theoretical deliberation, i.e. deliberation about whether to believe $p$, has some interesting features: It seems virtually impossible for practical considerations to effectively enter into them. Be the practical consequences ever so drastic, it is said, you cannot form beliefs at will. This is an empirical claim concerning our psychology. But if normative reasons have to be such that they can motivate creatures like us (i.e. be explanatory reasons for beliefs of ours), if they moreover have to be such that they can do this in "full daylight", i.e. through conscious processes of deliberation (and not just "secretly" or subconsciously), then this shows that there aren't any normative practical reasons for belief. ${ }^{19}$

\subsection{Reasons, Evidence, and Inference}

Above, we used "speaking for" to characterize the relation between a normative reason and what it is a reason for. Many hold that, in its full generality, this relation cannot be further analysed. But this is not so clear when it comes to reasons for belief. Here, a natural idea to start with is the following:

(Inf) If $p$ is a reason for believing $q$ then there is $a$ valid inference from $p$ to $q$.

But it is far from clear how to go about developing this plausible thought into a full analysis of the reasons-for-belief relation. ${ }^{20}$ Even when concerned with deductively valid inference only, there are classical difficulties. For instance, as Harman (1986, ch. 2) observes, even if you believe both that $p$ and that if $p$ then

\footnotetext{
18 The worry here is, in effect, that there would be what we elsewhere have called a "regress of motivations" (cf. Glüer and Wikforss 2009).

${ }^{19}$ McHugh (2013) argues that it does not hold in full generality that practical considerations cannot motivate belief through deliberation. He for instance discusses an example where you have less than conclusive evidence to the effect that a good friend of yours has committed some atrocity. Even if the evidence is strong enough to normally justify forming the belief that the person is guilty, McHugh argues, it not only is the case that it would be better to refrain from forming the belief if it concerns your good friend - when deliberating on the question of your friend's guilt it is moreover psychologically possible to be motivated by this consideration.

${ }^{20}$ As formulated, (Inf) might also seem to be a principle limited to reasons for first order belief. When forming a second order belief such as the belief that I believe that $p$, there (usually) is no valid inference from $p$ to I believe that $p$ (cf. Pryor 2013). But it is not so clear whether having a first order belief provides its subject with a reason for believing that she has that belief in the first place. It is, it seems to us, not even clear whether having the first order belief justifies having the second order belief. For a related discussion, see Byrne (2011).
} 
$q$, , $q$ might be so absurd that instead of having reasons to believe $q$, you have reason to abandon either $p$ or if $p$ then $q$. Moreover, many feel that even for purely deductive matters, (Inf) cannot be made into a bi-conditional - given our cognitive limitations, it is argued, we do not have reasons to believe all logical consequences of our beliefs (see, for instance, Harman 1986, ch. 2, Kelly 2006). Let's call a problem like this a "remoteness problem". A remoteness problem arises if our candidate for the reasons-for-belief relation relates the contents of our actual beliefs to propositions so "remote" from them that it seems intuitive to say that we do not have any reasons to believe the remote propositions. But remoteness is relative: If having reasons is a function of remoteness and you are an accomplished logician, while I am not, believing $p$ might give you, but not me, a reason to believe $q$. Even if such relativism might not strike everyone as objectionable, we should be wary of the most obvious way of spelling out what not being too remote precisely amounts to: if $q$ in fact follows from $p$, it might be thought, you have a reason for believing $q$ only if you also believe that it follows from $p$. Requiring belief in any such "bridge principle" threatens to lead into Carroll-style infinite regress. ${ }^{21}$

Matters do not get easier once we think about all the reasons falling short of deductively implying what they are reasons for. Many think that reasons for believing $p$ need to be, or provide, evidence for $p$. Thus, Thomas Kelly writes in his Stanford article on evidence: "Indeed, it is natural to think that 'reason to believe' and 'evidence' are more or less synonymous, being distinguished chiefly by the fact that the former functions grammatically as a count noun while the latter functions as a mass term" (Kelly 2009, 5). But there are many notions of evidence, and not all of them might be equally helpful in characterizing the reasons-for-belief relation. ${ }^{22}$

According to Williamson (2000), evidence is always propositional, and a subject $S$ 's evidence consists of the propositions $S$ knows. It is common to think of evidential relations between propositions as relations of implication and

\footnotetext{
21 Carroll 1895
}

22 See Achinstein (2001) for a systematic investigation into a variety of conceptions of evidence. Kelly (2006) provides a survey of the theory of evidence. 
probabilification. ${ }^{23}$ Such relations, one might then think, are relations obtaining between propositions independently of whether any subjects believe those propositions. The resulting conception of evidence would therefore be an objective conception of evidence. Probabilification, however, is a worldly matter: In worlds very different from the actual world, what makes what more probable and, thus, what is evidence or reason for what, can be very different. Many think that reasons relations cannot be hostage to the world in this way. This is supposed to become especially clear when considering so-called demon worlds where a subject $S_{1}$ is thought to have precisely the same evidence as another subject $S_{2}$ has in the actual world. Especially epistemologists of a more internalist stripe take it to be intuitively clear that such scenarios are possible. But then, being in a demon world cannot make the difference to a subject's reasons that an objective conception of evidence would predict.

And there might be trouble even at home. As soon as there are relations of probabilification in our world that we, or at least some of us, do not know about, we will get remoteness problems here, too. For clearly, many think, there will be situations - let's call them "remote cases" - where the probability of $q$ given $p$ is high, but nevertheless a subject believing $p$ has no reason to believe $q$ - because she is completely ignorant of the connection. However, once we countenance an externalist, wordly element in the reasons-for-belief relation, we might also relocate the ignorance, so to speak: we could treat remote cases as cases where the subject does indeed have a reason, but does - in a sense to be further clarified - not know that she does.

Now, if we think about reasons for belief in terms of objective evidential relations between propositions, there might be rather little temptation to construe the reasons-for-belief relation itself as normative. On such a conception, what is a reason for what is a completely objective matter independent of our actual psychology. Of course, one might think that our beliefs need to instantiate the abstract pattern of evidential connections to at least a certain degree to even be beliefs. ${ }^{24}$ Or one might think that - for some reason - our actual beliefs ought

\footnotetext{
${ }^{23}$ A natural idea then would be to try to use some form of Bayesianism to characterize what a subject has reason to believe. For a recent defense of this idea, see Brössel et. al 2013.

${ }^{24}$ We defend such a Davidsonian position in our 2009. Such a position is also occupied by some normativists, such as Wedgwood (2007).
} 
to instantiate this pattern, or that it would be good if they did - for instance, because that raises their chances of being true. Such instantiation, that is, might be what ought to be achieved given a certain goal, for instance that of truth. The idea would be that, given certain goals, certain norms for belief can be derived from the obtaining of reasons relations. But such norms would be purely instrumental. This is not the kind of normativity we were looking for. ${ }^{25}$

Remoteness problems can however be taken to show quite the opposite: Kelly uses remoteness problems to argue that the reasons-for-belief relation cannot be analysed by means of an objective conception of evidence. Rather, what we need is a subjective conception of evidence according to which evidence itself is a normative concept (cf. Kelly 2007, 467; 2009, 25). But why would going subjective on evidence imply using a normative conception of evidence? On the assumption that 'evidence' and 'reasons for belief' are basically synonymous, Kelly argues that we are "not entitled to simply assume that there is a nonnormative notion of evidence that stands in exactly this relation to the normative concept of a reason for belief' (Kelly 2007, 469, emph. added). Remoteness problems are then marshalled to show that a non-normative notion of evidence gets the extension of reason for belief wrong. And since the latter is a normative concept, the former needs to be one, too. But this just takes the normativity of reasons for granted - and thus begs the question we are concerned with in this article. ${ }^{26}$

\subsection{Summary: Normative reasons for belief?}

So far, our question has been whether the claim that reasons for belief are essentially normative can be cashed in terms of the distinction between explanatory and normative reasons. We have argued that the objectivity and

${ }^{25}$ This is precisely how Frege (1918) came to conceive of the "laws of logic" and their relation to our actual psychology. The laws himself he construed as "laws of truth" obtaining in complete independence from our psychology. Nevertheless, he thought that instrumental rules for the "pursuit of truth" could be derived (for a little more on Frege, and the influence of Husserl on Frege's thinking on these matters, see Glüer and Wikforss 2009).

${ }^{26}$ Brössel et. al. (2013) argue that the subjectivity required to deal with remoteness can be captured by means of a Bayesian model of what a subject has evidence for believing. Here, the evidence relation is not hostage to the world, but fully determined as a function (obeying the probability calculus) of the subject's beliefs. The authors then argue that the relation is objective in the sense required for conceiving of epistemic rationality as a form of instrumental rationality. But this again means that the relevant norms derivable from a given evidence relation are purely instrumental. For more on epistemic reasons and instrumental rationality, see Kelly 2003; 2007, Leite 2007. 
same-relation requirements put considerable pressure on the applicability of this distinction to reasons for belief, and that reasons for belief are most plausibly thought of as propositions. We can then say that having propositional attitudes provides subjects with reasons, and if a subject forms the belief she has a reason for (and does so for that reason) then having that reason explains her belief. This leaves it open to draw some distinction between such propositions in order to have a distinction parallel to that between normative and explanatory reasons for action - for instance, we might say that a proposition $p$ is a "normative" reason for believing $q$ only if the subject knows that $p$, or only if $p$ is true. But if the reasons-for-belief relation is best understood as a relation between propositions simpliciter, most probably as an evidence relation, it is not at all clear that the relation itself is essentially normative in any substantive sense. Rather than directly implying any oughts for belief, such a relation might not allow for more than the derivation of instrumental norms contingent upon certain goals or values.

\section{Reasons for Belief and Normative Conceptions of Justification}

There is another strand of argument commonly employed to support the normativity of reasons claim, one that figures prominently within epistemology, deriving from the connection between reasons and epistemic justification. Although there are theories of justification that do not spell out justification in terms of reasons (such as versions of reliabilism), those that do spell out justification in terms of reasons (such as standard internalism) tend to be normativist. It is argued that the notion of epistemic justification is an essentially normative notion since it is directly connected with obligations and duties. ${ }^{27}$ To illustrate this, a parallel with moral justification is often suggested. For an action to be justified it is necessary that the action is not in violation of any moral rules or duties; similarly, it is argued, for a belief to be justified it must not be in

\footnotetext{
27 The point is often made by appealing to the meaning of the term 'justification'. Plantinga, for instance, writes that the term "suggests duty, obligation, permission and rights - the whole deontological stable" (1988: 2). Similar remarks can be found in Ginet (2985): 182, and Steup (1988). One might of course question the import of these linguistic considerations. For instance, Alston (1988) grants that 'justification' is a normative term, but concludes that instead of supporting deontologism this simply shows that epistemologists are speaking infelicitously when employing the term.
} 
violation of any epistemic rules or duties. ${ }^{28}$ Moreover, it is held, the subject must recognize this: She must have formed the belief as a result of guidance by the epistemic principles. This requires not only that the subject accepts the relevant epistemic norm but, also, that she has a meta-level capacity to recognize a reason as a reason. ${ }^{29}$

Let us, following Goldman, call this the "guidance-deontological" conception of justification, the GD-conception for short (Goldman 1999). Goldman suggests that the GD-conception of justification provides a main rationale for internalism, since the demand that there is guidance implies a knowability requirement, according to which the only facts that can serve to justify a subject's belief that $p$ are facts that are directly knowable - i.e. internal facts. His strategy is to question this very strong construal of the knowability requirement, arguing that external facts may fit the bill as well once the knowability requirement is properly relaxed. ${ }^{30}$ Our concern here, however, is not with the knowability requirement, but with the GD-conception of justification.

GD-theories of all stripes grant that there is an important relation between epistemic reasons and truth, between justification and truth. Unlike non-normativist theories, however, GD-theories suggest that the relation between justification and truth must be construed normatively. A central idea is that we, as epistemic subjects, have an obligation to try to believe that $p$ (if and) only if $p$ is true. According to Chisholm, for instance, every person is subject to an intellectual requirement: "that of trying his best to bring it about that, for every proposition $h$ that he considers, he accepts $h$ if and only if $h$ is true" (1976: 14). The reasonableness of a belief, on Chisholm's view, depends on the extent to which holding the belief fulfills this requirement. However, it is important to distinguish between two versions of the GD-conception, one weaker and one stronger. This distinction, in turn, depends on the role of the epistemic norms in the account of epistemic reasons and justified belief.

${ }^{28}$ For a classical defense of the deontological conception of justification see BonJour (1980), Chisholm (1975), Ginet (1975) and Pollock (1986). For a critical discussion see Alston (1988), Fumerton (2001), and Pryor (2001).

29 The requirement that reasons are recognized as reasons is central to the type of epistemic internalism that is called 'access internalism'. There are versions of internalism that do not include an access requirement. See for instance Conee \& Feldman (2001).

${ }^{30}$ For a discussion of the relation between deontological theories and internalism see Bergman (2006), chapter 4. 
When it comes to epistemic justification a distinction is standardly drawn between propositional justification and doxastic justification, where the former is a property of propositions, the latter a property of beliefs. ${ }^{31}$ The notion of 'propositional justification' is understood relative to a subject $S$, such that a proposition $p$ can be propositionally justified, relative to $S$ 's beliefs, even if $S$ does not believe that $p$ or does not believe that $p$ on the basis of the evidence. This corresponds to the notion of having a reason, mentioned in section 2.2 above: $S$ has (a certain degree of) propositional justification for $p$, if $S$ has reasons for $p$. Doxastic justification, by contrast, requires that $S$ believes that $p$, and that she does so on the basis of her evidence. Thus, a subject may have excellent reasons for her belief that $p$, but she may have formed the belief on some other, much weaker, grounds, or on no grounds at all (she may indulge in wishful thinking for instance). In such a case, the subject's belief is propositionally justified, but it lacks doxastic justification. Our concern, so far, has been with epistemic reasons relating to propositional justification, and we have not said anything about doxastic justification. Deontological theories, however, are not merely concerned with propositional justification but also with doxastic justification, since a central idea is precisely that the epistemic status of a belief depends on whether it was formed in response to the relevant epistemic norms.

Given this, we can distinguish between two versions of the GD-conception of epistemic reasons and justification. According to the weak GD-conception, propositional justification is construed in a non-normative way, along the lines suggested above, in terms of objective evidence relations. The essential normativity only enters once we speak of doxastic justification - once our concern is with believing for a reason. According to the strong GD-conception, by contrast, there can be no non-normative notion of justification: To say that the belief that $q$ justifies (provides a reason for) the belief that $p$, is to say that believing that $p$ on the basis of $q$ would be in accordance with the subject's

${ }^{31}$ For a discussion, see for instance Bergman (2006), 4-6, and Pryor (2001): 104. Sometimes doxastic justification is referred to as 'personal justification' (Audi 1993), and Conee \& Feldman (2004) speak of 'well-founded beliefs', reserving the notion of justification for propositional justification. 
epistemic duty, it is what she ought to do (or, on a weaker construal, she is permitted to have the belief). ${ }^{32}$

There are problems that afflict both versions of the GD-conception deriving from the very idea that belief formation is rule guided. As mentioned in section 2.4, there is the question of doxastic voluntarism, whether we can believe at will. The idea that one ought to form one's beliefs in certain ways, seems to presuppose that one can control what one believes, at least on the principle that 'ought' implies 'can', and there are powerful objections against doxastic voluntarism. ${ }^{33}$ In addition, there is the concern that all GD-conceptions imply a view of epistemic reasons and justification that is much too cognitively demanding. Rule guidance, plausibly, requires both that the subject accepts the rule and that this acceptance of the rule provides a reasons explanation of her Eing. ${ }^{34}$ The generic guiding rule takes the form 'Do $\Theta$ when in conditions C'. To be guided by the rule, therefore, the subject also needs to have a belief as to whether conditions $\mathrm{C}$ are met. Applied to the case of belief formation, this requires that the subject is able to have second-order beliefs about the relations among her first-order beliefs. This would seem to exclude not only small children from having justified beliefs, but also individuals who are incapable of forming second-order beliefs (such as people with severe autism). ${ }^{35}$ It has been suggested that the view can be made less demanding by appealing to the idea that the rules need not be explicitly endorsed, and that it is sufficient that there is 'implicit' rule

\footnotetext{
32 Both versions of the GD-conception, notice, must be distinguished from the idea that the epistemic norms derive from the ethics of belief. Thus, Clifford's famous defense of the ethics of belief seems to presuppose a wholly non-normative conception of evidence and justification. For this reason it is a mistake to construe Clifford as a prime opponent of a deontological conception of justification (this is noted by Nottelmann (2013): 2227). Deontological theories of justification should also be distingushed from virtue theories. Whereas both types of theory appeal to the central role of epistemic blame and responsibility, virtue theories do not insist that there must be norm guidance (although there are attempts to combine the two, see Greco (1993)).

33 For a classical statement, see Alston (1988) who argues that deontological theories of justification are viable "only if beliefs are sufficiently under voluntary control to render such concepts as requirement, permission, obligation, reproach, and blame applicable to them" $(1988,259)$. Alston goes on to argue that doxastic voluntarism is false and that, therefore, deontological theories cannot be upheld. For a recent defense of epistemic deontologism against this objection see Feldman (2008) and Steup (2008).

34 See Glüer \& Wikforss (2009).

35 As noted above, the worry is not merely that second-order beliefs are required, but that each level of belief formation would seem to require a higher order belief. For worries concerning the need for higher order beliefs see Alston (1988); Bergmann (2006); Schmitt (2001).
} 
following. 36 The question is whether the notion of 'implicit' rule following can be spelled out in such a way that the important distinction between being guided by a rule and merely acting in accordance with one can be sustained. ${ }^{37}$ We shall set these problems aside here however. Instead, we shall discuss the GD-conception of epistemic reasons and justification as such.

\subsection{The weak GD-conception}

A version of the weak GD-conception of justification has been defended by Matthias Steup (1988). ${ }^{38}$ According to Steup doxastic justification is a matter of epistemic duty fulfillment. The duties are the ones that stipulate what one ought to do in the pursuit of truth: To believe that, and only that, which one has evidence for. The central epistemic norm, on Steup's view, is therefore the norm of sufficient evidence:

(Ne) $S$ ought to believe that $p$ iff $S$ has sufficient evidence that $p$.

All subjects are bound by this norm, according to Steup, independently of cultural context. Thus, even a subject in a culturally isolated situation where everyone believes in witchcraft is required to believe only that which has sufficient evidence. If the subject believes that there is such a thing as witchcraft, then it may be that her peers would consider the belief to be epistemically justified but it would nevertheless be epistemically incorrect - she would have failed to do her duty and have formed a belief she ought not hold. In retrospect, therefore, we have every right to blame the subject, epistemically: "The evidence for this belief was worse than poor. There actually was no reason at all to believe in witchcraft" (1988: 78). Steup's deontological account of doxastic justification, therefore, presupposes an objective notion of evidence and reasons, one that is

\footnotetext{
${ }^{36}$ See for instance Greco (1993), who argues that justification depends on following epistemic norms, but suggests that there is no requirement that the subject has explicit knowledge of the relevant norms. Instead, Greco argues, it is sufficient that the subject 'countenances' these rules: "The norms that we countenance are the norms that we follow when we reason conscientiously" (1993: 425). However, Greco (2002) drops the talk of following rules altogether and appeals simply to the subject's virtues.

${ }^{37}$ For some skepticism see Glüer \& Wikforss (2009).

${ }^{38}$ See also Steup (2001). Another good example can be found in Feldman (1988) and (2008) who proposes a combination of evidentialism and deontologism. For a related view, see Leite (2008). In the debate over the normativity of belief, the weak GD-conception is typically assumed. See for instance Wedgwood (2007).
} 
not dependent on what the subject takes to be a reason, and he employs this to formulate the relevant epistemic norm.

This means that as long as we are concerned with propositional justification, theories based on the weak GD-conception and non-normativist theories will be co-extensional. That is, on the assumption that the notion of evidence, appealed to in the epistemic norms such as (Ne), is the same as that employed by the non-normativist about reasons, the same set of beliefs will be propositionally justified and rational: the set of justified beliefs will be the set of beliefs for which the subject has sufficient evidence. ${ }^{39}$ As long as we hold the notion of evidence steady between the normativist and the non-normativist, the norm therefore does not make a difference when it comes to propositional justification.

When it comes to doxastic justification, however, the norm can make a difference since the idea behind the weak GD-conception is precisely that believing for a reason involves believing as a result of rule guidance. ${ }^{40}$ Depending on how the non-normativist spells out the relevant notion of believing on the basis of a reason, the normativist and the non-normativist accounts may not be co-extensional. For instance, the non-normativist may adopt a causal view of the basing relation, according to which a belief is based on a reason if and only if it is caused (in the right way) by a reason that the subject has. ${ }^{41}$ Since this view of the basing relation implies that doxastic justification does not require any ruleguidance, it is very likely that it will not be co-extensional with the weak GDconception. For instance, the causal view allows for the possibility that small children (and others who do not know anything about epistemic norms and are not capable of second-order beliefs) have beliefs that are doxastically justified,

\footnotetext{
${ }^{39}$ Since Steup speaks of reasons in terms of objective evidence it is very plausible that this is how he construes epistemic reasons.

${ }^{40}$ Nottelmann (2013) discusses the deontological conception of justification, and notes that some philosophers (such as Feldman) appeal to epistemic oughts while endorsing a non-deontological conception of evidence and reasons (2013: 2231). Nottelmann suggests that this type of view falls short of a deontological account of epistemic justification, and argues that a proper deontological view requires construing justification in terms of blameless belief (as on the strong GD-conception). However, it is of importance here to distinguish propositional justification from doxastic justification: With respect to the latter the rules will matter even if the starting point is a non-normative conception of evidence. Nottelmann therefore fails to draw the distinction between the weak and the strong GDconception.

${ }^{41}$ It is much debated how the basing relation is to be construed but the causal view (and versions thereof) is very commonly endorsed. For an overview and discussion see Korcz (2010).
} 
whereas accounts of justification that require rule guidance may not. However, as noted above, that co-extensionality fails here would seem to be a prima facie problem for the GD-conception.

The problem is not just that large groups of individuals would seem to be excluded from having justified beliefs, but that it is unclear why rule guidance should be able to change the doxastic justification of the belief. Imagine a subject who has excellent reasons for the belief that $p$, and these reasons cause her (in the right way) to form the belief that $p$. In such a case her belief that $p$ can be explained by reference to her reasons: She believes that $p$ because she believes that $q, r, s$, etc. This explanation, it would seem, is an instance of an ordinary folkpsychological reasons explanation, where a belief is explained by reference to further belief. And that such an explanation is available would seem to be sufficient to make the belief rational even if there is no rule involved: If asked why I believe there is beer in the fridge, it would seem perfectly sufficient to reply that I looked in the fridge (or that Bob told me he just bought some). ${ }^{42}$ After all, it has already been granted that the evidence relation between the propositions may be in place independently of the rules and independently of the subject's beliefs about her first-order reasons. Why, then, should it be the case that the belief is reason based, and rational, only if there is guidance by rules? Thus, while it seems likely that on the weak GD-conception, the norms do make an extensional difference to doxastic justification when compared to nonnormative conceptions employing the same notion of evidence, this might turn out to be more of a problem than an advantage. ${ }^{43}$

Moreover, the weak GD-conception might turn out to be rather inhospitable to some of the very intuitions supposed to support deontological conceptions in the first place. Consider demon worlds again. These types of scenarios are often appealed to in order to trigger deontological intuitions. The demon world may be such that the demon feeds the subject beliefs about an

42 Alston (1985): 82-82 stresses this. This is not to say, naturally, that the presence of a secondorder belief may not change the justificatory status of the first-order belief. For instance, if the subject believes that her fridge perceptions are utterly unreliable, then this arguably changes the justificatory status of the perception. It does not follow, however, that second-order beliefs are necessary for doxastic justification. For a defense of the opposite view see Leite (2008), who argues that the basing relation always requires that the subject believes that her reasons are reasons.

${ }^{43}$ We discuss a related point in Glüer \& Wikforss (2013): 90-93. 
external environment that is not there, providing her with all the same beliefs as her twin in a non-demon world. On an objective conception of epistemic reasons or evidence it might easily follow that a large part of the subject's beliefs will actually fail to be reason based (in particular, her perceptual beliefs and her memory beliefs), since the normal probabilistic relations between (many of) the empirical propositions have been undermined (see section 2.5). For instance, in a demon world the fact that it looks to the subject as if there is beer in the fridge does not provide (objective) evidence for the belief that there is beer in the fridge. According to the deontologist this shows that we need a different notion of doxastic justification, one that allows us to say that such a subject is fully rational and holds justified beliefs. However, it is hard to see how the deontological element of the weak GD-conception could allow for this. As long as the same (objective) notion of evidence is employed, the subject in the demon world will not have evidence based beliefs either way. Hence, even if they are rule-guided, her beliefs will - contrary to the intuitions marshalled by the deontologist - not be doxastically justified. ${ }^{44}$

The weak GD-conception, therefore, can be characterized as an unsuccessful attempt to marry a deontological conception of doxastic justification with an objective conception of epistemic reasons and justification: On the one hand, the deontological element implies that a subject whose belief formation appears to be fully rational, explained by the evidence she holds, falls short of having beliefs that are doxastically justified because the required rule guidance goes missing. On the other hand, since the deontological component is disconnected from the notion of propositional justification, it fails to satisfy the normativist intuition that there is a connection between blameless belief and justification.

\footnotetext{
${ }^{44}$ Some of those who hold an objective account of justification have argued that we can simply add a second notion of justification in order to account for the demon worlds. See for instance Goldman (1988) who distinguishes between strong justification and weak justification, where the former is construed in terms of reliability, the latter in terms of blameless or non-culpable belief. Proponents of the weak GD-conception can make this move too, of course, but what would be required is precisely an additional notion of justification, one that is distinct from doxastic justification as construed by the weak GD-conception.
} 


\subsection{The strong GD-conception}

The strong GD-conception, by contrast, gives a thoroughly deontological account of epistemic justification, freeing it from all external contingencies and construing it directly in terms of deontological notions (see for instance BonJour 1980, Folely 1985, and Ginet 1985). On this view, the subject has doxastic justification for her belief that $p$, to the extent that she has tried to do what she takes to be her epistemic duty, to the extent that the belief formation is blameless or responsible. The view provides a fully subjective account of justification since the very notion of an epistemic reason is to be understood in terms of what the subject takes to be a reason. On the strong GD-conception, therefore, propositional justification is no less subjective than doxastic justification: To say that the subject has reasons for the belief that $p$, is to say that she thinks she has grounds (beliefs and experiences) such that she ought to believe that $p$ given these grounds. If she forms the belief that $p$ in response to this, her belief is doxastically justified. What matters to justification, then, is not that the belief that $p$ actually satisfies some principle or norm but that it is judged to do so. ${ }^{45} \mathrm{In}$ an evil demon scenario the subject's beliefs will be justified to the extent that her belief formation was guided by (what she takes to be) the epistemic norms, independently of whether any objective evidence relations hold among the propositions of her beliefs. The strong GD-conception, therefore, is fully internalist, in the sense that it implies that justification supervenes on the internal, mental states of the subject. ${ }^{46}$

One of the proponents of the strong GD-conception of justification, arguably, is BonJour (1980). ${ }^{47}$ According to BonJour, the concept of epistemic

45 Schmitt (2001) calls this view 'epistemic perspectivism', and characterizes it as the view that when it comes to the property of being epistemically justified "thinking makes it so: a subject's belief is justified in virtue of being sanctioned by the subject's outlook or perspective on justification" (180). See also Alston (1985): 83.

${ }^{46}$ Conee \& Feldman (2001) suggest that evidentialism can be combined with a fully internalist conception of justification, according to which the justificatory status of $S$ 's beliefs strongly supervenes on her mental states. This supervenience claim, clearly, presupposes a non-objective conception of evidence, and it is difficult to see how this is compatible with Conee \& Feldman's evidentialist position. Indeed, they themselves note that the fact that $p$ justifies $q$ is "not itself an internal state" (2001): 11 .

${ }^{47}$ Since the distinction between the weak GD-conception and the strong one is not always made explicit, there are some uncertainties as to which deontological theories of justification qualify as strong and which are merely weak. Nevertheless, in addition to Bonjour, versions of the strong GD- 
justification is fundamentally normative: "It has to do with what one has a duty or obligation to do, from an epistemic or intellectual standpoint" (1980: 55). Following Chisholm, BonJour suggests that we have an intellectual duty to accept beliefs that are true, and reject beliefs that are false. A subject who ignores this, and accepts beliefs on some other basis, is violating her epistemic duty, she is being epistemically irresponsible. To do one's duty, therefore, one needs to have an adequate reason for thinking that a belief is true. That is, the subject needs to have the second-order belief that she has reasons for her first-order belief. ${ }^{48}$ BonJour contrasts this account of justification with that of reliabilism, according to which there is no requirement that the subject possesses an adequate reason to think that her belief stands in a reliable relation to the world. Reliabilism, he argues, provides a revisionary account of epistemic rationality, since it implies that a person may be completely irrational and irresponsible in accepting a belief, judged by her own conception of the situation, and yet be epistemically justified. For instance, a subject may believe herself to have the power of clairvoyance, and form beliefs on this basis, even though she has no reasons to believe that she has this power. On the reliabilist view, BonJour argues, such a subject is nevertheless justified if indeed she is clairvoyant and her beliefs are formed in a reliable way. According to BonJour this leads to a basic objection to externalist theories of justification: "external or objective reliability is not enough to offset subjective irrationality" (1980: 61).

It is important, here, to keep distinct a reliabilist account of justification (along the lines defended by Goldman (1979)) and an objective, externalist conception of epistemic reasons, along the lines suggested above. Both types of theories imply that (many of) the subject's beliefs will lack (propositional and doxastic) justification in demon worlds - reliabilism because the beliefs will not be reliable, reason externalism because the evidence relations do not hold in this extreme scenario. However, it is much less clear that all externalist theories will

conception are plausibly defended in Chisholm (1975), Folely (1985), Ginet (1975), Greco (1993) and Pollock (1986).

${ }^{48}$ See also Bonjour (1985) where Bonjour defends a coherentist version of internalism. Although Bonjour spells out the notion of coherence in non-normative terms, appealing to the notion of inferential connections, he makes it quite clear that coherence is not sufficient for justification. In addition, according to Bonjour, the fact that the belief coheres must be cognitively accessible to the believer. To have a reason, thus, it is required that the subject has a set of metabeliefs $(101-106,116-$ 119). 
have difficulties accounting for the other types of cases discussed by BonJour, such as the clairvoyance case. If $S$ believes that the president is in town without having any evidence for this belief, and having much evidence against it, then, on an objective conception of epistemic reasons, this must count against $S$ 's belief being justified - even if she is perfectly reliable as a result of her capacity for clairvoyance. Hence, while (versions of) reliabilism may imply that a belief can be justified despite the subject having no evidence for it, or having strong evidence against it, an externalist conception of epistemic reasons, does not need to have this implication. It is therefore not necessarily the case that there will be scenarios where, as BonJour puts it, "external reliability is enough to offset subjective irrationality", precisely because an objective construal of epistemic reasons might forge a connection between external reliability and rationality.

To motivate the strong GD-conception, therefore, it is not sufficient to appeal to the clairvoyance example; instead, one must appeal to demon worlds. The main advantage of the view is that it supports the idea that the subject in the demon world can have reasons for her beliefs, and have doxastically justified beliefs, to the very same extent that her twin in a non-demon world. However, it should be clear that this accomplishment comes at the price of disconnecting epistemic reasons and justification from truth and truth conduciveness. This means that by making epistemic reasons and justification wholly subjective, the strong GD-conception may preserve our intuitions about evil demon scenarios, but it will give counterintuitive results in other cases. If a subject has an epistemic reason for her belief that $p$ to the extent that she thinks she has an epistemic reason, then much of what we will consider to be irrational belief will come out as rational and reason based. As stressed by Alston (1988), what the subject thinks is evidence will depend on her culture, upbringing and general intelligence. In the case of cultural isolation, for instance, someone may accept the traditions of her community as authoritative, and do her best to form her beliefs in accordance with what these traditions require - with the result that she is not believing in a truth conducive way, not believing on the basis of objective epistemic reasons (1985: 67-68; 1988: 286-287). ${ }^{49}$ These types of

49 Alston takes this to be a central objection to deontological justification. This type of justification, he writes, "is sensitive to cultural differences because it depends on what can reasonably 
cases, Alston argues, show that epistemological and deontological justification come apart. In general, it is clear that a belief may be blameless, in the sense that the subject has done everything she believes she ought to do, without being based on truth conducive grounds. ${ }^{50}$

A related difficulty concerns the fact that the subject is required to have second-order beliefs about the reasons for her first-order beliefs. There is a very immediate threat of a regress here, since the question arises what reasons she has for the second-order belief that she has good reasons for her first-order belief. In addition, of course, the subject needs to believe that the epistemic principle she has chosen is the correct principle and this, also, is a belief that requires grounds. ${ }^{51}$ This problem, familiar from the literature, derives from the attempt to give a purely subjective construal of doxastic justification, freeing it from dependency on external contingencies. A similar regress afflicts all versions of access internalism, according to which a justified first-order belief requires that the subject has a justified second-order belief about the justificatory status of the first-order belief. ${ }^{52}$ However, while the access internalist (who does not endorse the strong GD-conception) may argue that the regress can be stopped simply by denying that the justification of second-order beliefs need be accessible, a similar move is not available here. ${ }^{53}$ After all, the idea is that justification consists in blameless belief and that blameless belief is belief guided by (what the subject takes to be) the epistemic norms. Thus, on the strong GDconception the accessibility requirement does not simply derive from the idea

be expected of one, and that in turn depends on one's social inheritance. But truth conductivity does not so depend. Hence they can diverge" (1988: 287). See also Alston (1985).

${ }^{50}$ For a discussion see of how blameless belief and justification may come apart see Plantinga (1988), Pryor (2001): 114-115, Fumerton (2001), Nottelman (2013) and Schmitt (2001). Pryor takes this to be an important objection to all deontological conceptions of justification. Of course, depending on the details of the position, it is possible that the strong GD-conception could allow for some gap between blameless belief and justified belief. For instance, perhaps the subject is unable to follow the rules she has adopted simply because she cannot fully control her belief formation, in which case the belief would be blameless but unjustified. However, this possibility will not satisfy those, like Alston, who think that we need a rather different gap: i.e. that between holding a justified belief and holding a belief one thinks is justified.

${ }^{51}$ See Folely (1993) for a discussion of problems concerning how to choose the proper epistemic principle.

52 For a discussion of this regress problem see Bergman (2006) Boghossian (2001) and Wedgwood (2007). Bonjour (1985) attempts to avoid the regress by denying that second-order beliefs are justified in the same way as the first-order beliefs (102).

${ }^{53}$ Of course, those who reject the access requirement in the first place, will object that if the requirement is not needed for second-order beliefs, then it is not needed for first-order beliefs either. 
that reasons should be knowable from the first-person point of view, but from the very idea that something is a reason if and only if it is taken to be a reason. This idea, in combination with the assumption that the subject needs to have reasons for the meta-level belief (the belief that $q$ is a reason for $p$ ), lies behind this regress. To solve it, one would have to grant that the subject can have a reason $q$ for her belief that $p$, without having to have a reason based belief that she has such a reason. But to grant that, of course, the strong GD-conception would have to be rejected..$^{54}$

The attempt to defend normativism about epistemic reasons via normativism about epistemic justification is therefore problematic. The problem can be put in terms of a dilemma: Either the normativist accepts that there is a non-normative construal of epistemic reasons and propositional justification, in which case the added norms might not do any real epistemic work; or the normativist rejects all non-normative, objective construals of epistemic reasons, in which case the resulting conception of a reason threatens to become thoroughly subjective and disconnected from truth. At the present stage of debate, the appeal to norms in the account of justification, whether propositional or doxastic, thus appears to be less than well-established, leaving room for genuinely non-normativist accounts. ${ }^{55}$

\section{Conclusion}

We have considered two important strategies for defending the idea, widely endorsed, that epistemic reasons are essentially normative. First, we have examined the proposal that the distinction between explanatory reasons and "normative" reasons, commonly appealed to in the case of reasons for action, can be used to spell out and motivate the view that reasons for belief are normative.

${ }^{54}$ For instance, Leite (2008) proposes a solution to the regress problem, arguing that there is an internal connection between justified belief and responsible belief and that this requires meta-level beliefs. However, since the solution presupposes an objective conception of evidence it does not solve the regress problem afflicting the strong GD-conception (even if it solves the problem as it arises within the context of the weak GD-conception).

55 As noted above, when people speak of epistemic normativity, the normativity is sometimes derived from the ethics of belief, whereas this article is concerned with the idea that epistemic reasons as such are normative. Similarly, the term 'epistemic deontologism' is sometimes used to refer not to deontological theories of justification (the topic of this article), but to deontological theories of belief (see for instance Nottelmann $(2007 ; 2013)$ ). 
We have found no compelling way of doing this. Second, we have examined the proposal that the connection between epistemic reasons and justification supports the normativist account of reasons. We have distinguished two attempts to tie epistemic justification to norms, the weak and the strong GDconception, and argued that both of them are fraught with difficulties. Naturally, there may be other strategies that could be employed to support normativism about epistemic reasons, but we take the discussion above to show at least that the position cannot be taken for granted (as it so often is) - but rather is in need of much more detailed attention and motivating argument.

\section{References}

Achinstein, P. 2001. The Book of Evidence. Oxford: OUP.

Alston, W.P. 1985. “Concepts of Epistemic Justification”, The Monist 68: 57-89.

— 1988. "Deontological Justification”, Philosophical Perspectives 2, Epistemology: 257-299.

Anscombe, G.E.M. 1958. Intention. Oxford: Blackwell.

Audi, R. 1993. The Structure of Justification. Cambridge: Cambridge University Press.

— 1988. "The Ethics of Belief: Doxastic Self-Control and Intellectual Virtue", Synthese 161: 403-418.

Bergmann, M. 2006. Justification without Awareness. Oxford: Clarendon Press.

Brewer, B. 1999. Perception and Reason. Oxford: OUP.

— 2011. Perception and its Objects. Oxford: OUP.

Boghossian, P. 2001. "How Are Objective Epistemic Reasons Possible?”, Philosophical Studies 106: 1-40.

Bonjour, L. 1980. "Externalist Theories of Empirical Knowledge”, Midwest Studies in Philosophy 5: 53-73. 
— 1985. The Structure of Empirical Knowledge. Cambridge, Mass: Harvard University Press.

Booth, A. R. 2011. "Epistemic Ought is a Commensurable Ought", forthcoming in European Journal of Philosophy. Published online : 21 DEC 2011, DOI: $10.1111 /$ j.1468-0378.2011.00501.x

Brandom, R. 2000. Articulating Reasons: An Introduction to Inferentialism. Cambridge, MA: Harvard University Press.

Brössel, P., Eder, A.-M., Huber, F. 2013. “Evidential Support and Instrumental Rationality", Philosophy and Phenomenological Research 87: 279-300.

Burge, T. 2010. Origins of Objectivity. Oxford: OUP.

Byrne, A. 2011. "Transparency, Belief, Intention", Proceedings of the Aristotelian Society, LXXXV: 201-220.

Carroll, L. 1895. "What the Tortoise Said to Achilles", Mind 4: 278-80.

Chisholm, R. Theory of Knowledge. Englewood Cliffs: Prentice-Hall.

Crane, T. 2009. “Is Perception a Propositional Attitude?” Philosophical Quarterly 59: 452-469.

Conee, E. and Feldman R. 2001. "Internalism defended”, American Philosophical Quarterly 38: 1-18.

— 2004. Evidentialism: Essays in Epistemology. Oxford: OUP.

Dancy, J. 2000. Practical Reality. Oxford: OUP.

Davidson, D. 1983. “A Coherence Theory of Truth and Knowledge”, reprinted in Subjective, Intersubjective, Objective, Oxford: OUP 2001: 137-153.

Feldman, R. 1988. "Epistemic Obligations”, Philosophical Perspectives, Vol.2, Epistemology: 235-256

— 2008. "Modest Deontologism in Epistemology", Synthese 161: 339-355. 
Finlay, S. and Schroeder, M. 2008. "Reasons for Action: Internal vs. External", The Stanford Encyclopedia of Philosophy (Winter 2012 Edition), Edward N.

Zalta (ed.), URL $=<$ http://plato.stanford.edu/archives/win2012/entries/reasonsinternal-external/>.

Folely, R. "What's Wrong with Reliabilism?”, The Monist 68: 188-202.

Frege, G. 1918. "Der Gedanke”. In Logische Untersuchungen, ed. G. Patzig, Göttingen: Vandenhoeck \& Ruprecht, 1986.

Fumerton, R. "Epistemic Justification and Normativity", in Knowledge, Truth, and Duty: Essays on Epistemic Justification, Responsibility, and Virtue, ed. M. Steup, Oxford: OUP.

Ginet, C. 1975. Knowledge, perception, and Memory, Dordrecht: Reidel.

— 1985. "Contra Reliabilism", The Monist 68: 175-187.

Glüer, K. 2009. "In Defence of a Doxastic Account of Experience”, Mind and Language 24: 297-373.

— 2011. Donald Davidson. A Short Introduction. New York: OUP.

— 2012. "Perception and Intermediaries", in Donald Davidson on Truth, Meaning, and the Mental, ed. by G. Preyer, New York: OUP, 192-213.

Glüer, K. and Wikforss, Å. 2009. "Against Content Normativity”, Mind 118, 2009: 31-70.

— 2013. "Against Belief Normativity”, in The Aim of Belief, ed. T H W Chan, Oxford: OUP: 121-146.

Goldman, A. 1979. "What Is Justified Belief?”, in. G. Pappas ed., Justification and Knowledge: New Studies in Epistemology, Dordrecht: Reidel: 1-23.

— 1988. "Strong and Weak Justification”, Philosophical Perspectives 2, Epistemology: 51-70. 
— 1999. “Internalism Exposed", The Journal of Philosophy 96: 271-293.

Greco, J. "Virtues and Vices of Virtue Epistemology", Canadian Journal of Philosophy 23: 413-432.

— 2001. "Virtues and Rules in Epistemology", in Virtue Epistemology. Essays on Epistemic Virtue and Responsibility, ed. A. Fairweather and L. Zagzebski, Oxford University Press: OUP: 117-141.

Harman, G. 1986. Change in View. Cambridge, MA: MIT Press.

Hattiangadi, A. Paper in this Volume ???.

Heuer, U. 2004. "Reasons for Actions and Desires", Philosophical Studies 121: 4363.

— 2013. “The Reasons that Can't be Followed: Comment on Joseph Raz's From Normativity to Responsibility", forthcoming in Jerusalem Review of Legal Studies.

Kelly, T. 2003. "Epistemic Rationality as Instrumental Rationality: A Critique.

Philosophy and Phenomenological Research 66: 612-640.

—, 2006. "Evidence", The Stanford Encyclopedia of Philosophy (Fall 2008 Edition), Edward N. Zalta (ed.), URL=<http://plato.stanford.edu/archives/fall2008/entries/ evidence/ $>$.

— 2007. "Evidence and Normativity: Reply to Leite", Philosophy and Phenomenological Research 75: 465-474.

Korcz, K.A. 2010. "The Epistemic Basing Relation”, The Stanford Encyclopedia of Philosophy (Spring 2010 Edition), Edward N. Zalta (ed.), URL = <http://plato.stanford.edu/archives/spr2010/entries/basing-epistemic/>. 
Leite, A. 2007. "Epistemic Instrumentalism and Reasons for Belief: A Reply to Tom Kelly’s 'Epistemic Rationality as Instrumental Rationality: A Critique’”, Philosophy and Phenomenological Research 75: 456-464.

— 2007. “Believing One's Reasons Are Good”, Synthese 161: 419-441.

Lenman, J. 2009. "Reasons for Action: Justification vs. Explanation”, The Stanford Encyclopedia of Philosophy (Winter 2011 Edition), Edward N. Zalta (ed.), URL $=<$ http://plato.stanford.edu/archives/win2011/entries/reasons-just-vs-expl/ $>$.

Lewis, D. 1996. “Desire as Belief II”, Mind 105: 303-313.

Martin, M.G.F. 2002. “The Transparency of Experience”, Mind and Language 17: $376-425$.

McDowell, J. 1994. Mind and World. Oxford: OUP.

— 1998. "Reply to Commentators", Philosophy and Phenomenological Research 58: 403-431.

McHugh, C. 2013. "The Illusion of Exclusivity", forthcoming in European Journal of Philosophy. Published online : 11 APR 2013, DOI: 10.1111/ejop.12032.

Nottelmann, N. 2007. "Introduction”, Synthese 161: 325-337.

— 2007. "The Deontological Conception of Epistemic Justification: A Reassessment”, Synthese 190: 2219-2241.

Olson, J. 2014. "The Metaphysics of Reasons", this volume ???.

Plantinga, , A. "Positive Epistemic Status and Proper Function", in Philosophical Perspectives 2, Epistemology: 1- 50.

Pryor, J. 2001. "Highlights of Recent Epistemology”, British Journal of Philosophy of Science 52: 95-124. 
— 2014. “Is There Immediate Justification?” In: Contemporary Debates in Epistemology, Second Edition. Ed. by M. Steup, J. Turri and E. Sosa. Malden, MA: Blackwell (First edition 2005). 202-222.

Pollock, J. 1986. Contemporary Theories of Knowledge, Totowa: Rowman \& Littlefield.

Raz, J. 2011. From Normativity to Responsibility. Oxford: OUP.

Reisner, A. 2009. “The Possibility of Pragmatic Reasons for Belief and the Wrong Kind of Reasons Problem", Philosophical Studies 145: 257-272.

Scanlon, T.M. 1998. What We Owe to Each Other. Cambridge, MA: The Belknap Press of Harvard University Press.

Schmitt, F. "Epistemic Perspectivism", reprinted in Epistemology: Internalism and Externalism, ed. H. Kornblith. Oxford: Blackwell: 180- 206.

Shah, N. and Velleman, D. 2005. "Doxastic Deliberation”, Philosophical Review, $114,497-534$.

Siegel, S. and Silins, N. 2013. "The Epistemology of Perception", forthcoming in The Oxford Handbook of Philosophy of Perception, ed. by M. Matthen, Oxford: OUP.

Smith, M. 1994. The Moral Problem. Oxford: Blackwell.

— 2003. "Humeanism, Psychologism, and the Normative Story", reprinted in Ethics and the A Priori, Cambridge: Cambridge University Press 2004, 146-154.

Steup, M. “The Deontic Conception of Epistemic Justification”, Philosophical Studies 53: $65-84$.

— 2001. "Epistemic Duty, Evidence, and Internality", in Knowledge, Truth and Duty, New York: OUP: 134-148.

Travis, C. 2004. "The Silence of the Senses", Mind 113: 57-94. 
Turri, J. 2009. “The Ontology of Epistemic Reasons”. Nous 43: 490-512.

Wedgwood, R. 2007. The Nature of Normativity, Oxford: OUP.

Williams, B. 1979. "Internal and External Reasons”, reprinted in Moral Luck, Cambridge: Cambridge University Press 1981, 101-113.

Williamson, T. 2000. Knowledge and its Limits. Oxford: OUP. 